\title{
Two new species of Agarics from India
}

\author{
Kaur NJ, Saini MK and Kaur H
}

Department of Botany, Punjabi University, Patiala-147002, India. E-mail: narinderjit06@gmail.com

Kaur NJ, Saini MK, Kaur H 2013 - Two new species of Agarics from India. Mycosphere 4(5), 856-863, Doi 10.5943/mycosphere/4/5/1

\begin{abstract}
Two new species belonging to genus Lepiota i.e. Lepiota punjabensis sp. nov. and genus Volvariella i.e. Volvariella indica sp. nov. have been taxonomically described and illustrated for the first time from India and reported as new to Science.
\end{abstract}

Key words - India - Lepiota - light spored agarics - taxonomy - Volvariella

\section{Introduction}

The genus Lepiota (Pers. ex Fr.) S.F. Gray (family Agaricaceae, tribus Lepioteae) is characterized by very small to large robust carpophores, white to variously colored, convex to applanate or campanulate pileus with characteristic squamules or floccose elements over its surface; typically free and light colored gills; annular veil present on stipe; spore print white, pale or rarely pinkish; basidiospores dextrinoid, always smooth without pore, small or large, no metachromatic reaction with cresyl blue; cheilocystidia mostly present; pleurocystidia occasional or absent; clamp connections present or absent (Pegler 1977). This genus is represented by 400 species the world over (Kirk et al., 2008).

The genus Volvariella Speg (family Pluteaceae) is characterized by small to medium or large fruiting bodies; convex to expanded, dry to viscid or smooth or scaly pileus; free, pink, crowded gills; central stipe; persistent veil present as volva; spore print sordid pink to cinnamon pink; basidiospores ovoid to ellipsoid, smooth, inamyloid; hymenophoral trama convergent type; pileus surface an undifferentiated repent epicutis of radially parallel hyphae; clamp connections mostly absent (Pegler 1977). This genus is represented by 50 species the world over (Kirk et al., 2008).

Punjab is situated in the North- Western corner of India having 22 districts. North- Eastern parts of Punjab Includes mainly the six districts- Hoshiarpur, Gurdaspur, Pathankot, Rupnagar, Fatehgarh Sahib and Patiala falling within an altitude range of $250 \mathrm{~m}$ to $700 \mathrm{~m}$. This area is very rich in mushroom diversity, as this area falls in the foothills of Shivalik hills. During the fungal forays to various localities of North Eastern Punjab, 10 collections have been made and Lepiota punjabensis and Volvariella indica are reported as new to Science and are taxonomically described in this paper. 


\section{Materials and methods}

Standard methods for collection, preservation and description of agarics were followed, using the terminology and Field key to mushroom collector given by Atri et al., (2005). The terminology used for describing the color tone of carpophores parts and spore print is after Kornerup and Wanscher (1978). The specimens were hot air dried at temperature between $45-50^{\circ} \mathrm{C}$ by using a specially designed wooden drier (Atri et al., 2005) using a low voltage (500 Watt) heater. Macroscopic examinations including habit, habitat, any color change on cutting or bruising, locality, field photographs, size of the carpophore etc were carried out on fresh specimens in the field. Microscopic details were studied from free hand sections mounted in $5 \% \mathrm{KOH}$, stained in cotton blue ( $0.16 \mathrm{~g}$ cotton blue dissolved in $100 \mathrm{ml}$ lactic acid). The identified specimens have been deposited in the Herbarium, Department of Botany, Punjabi University, Patiala (Punjab) India, under the Accession No. PUN. For taxonomic treatment, Singer (1986) and Kirk et al., (2008) have been followed. Microscopic details are shown in Figs 1-6.

\section{Taxonomic observations}

Lepiota punjabensis N.J. Kaur, M.K. Saini, N.S. Atri sp. nov. Fig. 1 (A-F); 2; 3. Mycobank no.: MB 804761

Etymology- The name of species is based on the area surveyed.

Pileus 2.0-6.3 cm broad, convex to flattened depressed, scaly, pileal veil present; Lamellae free, crowded, trabeculate, orange white to orange gray; stipe $6-11.5 \mathrm{~cm}$ long, $0.3-0.7 \mathrm{~cm}$ broad, white $\left(1 \mathrm{~A}_{1}\right)$ changing grayish red $\left(8 \mathrm{C}_{5}\right)$ to reddish brown $\left(8 \mathrm{D}_{6}\right)$ on bruising; annulate, annulus single, funnel shaped; basidiospores 3.58-4.48 $(5.37) \times 2.68-3.58 \mu \mathrm{m}$; cheilocystidia $12.5-18 \times 7.0-10$ $\mu \mathrm{m}$; clamp connections present.

Carpophores 7.0-12 cm in height. Pileus $2.0-6.3 \mathrm{~cm}$ broad, convex to flattened depressed at maturity, olive yellow centre $\left(3 \mathrm{C}_{6}\right)$; scaly, dull, grayish yellow $\left(3 \mathrm{~B}_{4}\right)$ squamulose scales present on offwhite background, more concentrated in the centre, scattered all over the surface; umbo absent; margin regular to irregular, splitting at maturity; surface moist; cuticle fully peeling; flesh upto $0.3 \mathrm{~cm}$ thick, offwhite changing to browing on exposure; pileal veil patch present in the centre of pileus and appendiculate veil type at the margins; taste and odour mild. Lamellae free, unequal, 4 lengths, crowded, orange white $\left(5 \mathrm{~A}_{2}\right)$ to orange gray $\left(5 \mathrm{~B}_{2}\right)$ at maturity, moderatey broad, upto 0.6 $\mathrm{cm}$ broad, trabeculae, forking and lamellulae present; gill edges smooth to lacerate, fragile. Stipe central, $6-11.5 \mathrm{~cm}$ long, $0.3-0.7 \mathrm{~cm}$ broad, white $\left(1 \mathrm{~A}_{1}\right)$ changing grayish red $\left(8 \mathrm{C}_{5}\right)$ to reddish brown $\left(8 \mathrm{D}_{6}\right)$ on bruising, equal in diameter throughout with spindle shaped swollen base, white cottony mycelial mats prominent at the base of the stipe, hollow, smooth, shining; annulate, annulus single, superior, funnel shaped when young, patchy at maturity. Spore print grayish orange $\left(5 \mathrm{~B}_{3}\right)$.

Basidiospores 3.58-4.48 (5.37) × 2.68-3.58 $\mu \mathrm{m}$ (excluding apiculus), $(\mathrm{Q}=1.36)$, ellipsoid, double walled, granulated; apiculate, apiculus upto $0.9 \mu \mathrm{m}$ long, mostly excentric. Basidia 10.74$21.48 \times 5.37-7.16 \mu \mathrm{m}$ clavate, half granular, 2-4 spored; sterigmata upto $1.8 \mu \mathrm{m}$ long. Pleurocystidia absent; Cheilocystidia $12.5-18 \times 7.0-10 \mu \mathrm{m}$, fusoid to ballon shaped, granular and encrustrated at apex, abundant. Gill edges heteromorphous. Carpophore context homoiomerous. Pileus cuticle cellular, each cell measuring 9. $-21 \times 10-18 \mu \mathrm{m}$; context made up of upto $5.37 \mu \mathrm{m}$ broad septate hyphae. Hymenophoral trama regular. Stipe cuticle hyphal, made up of longitudinally tangled upto $7.0 \mu \mathrm{m}$ broad septate hyphe; context made up of upto $13 \mu \mathrm{m}$ broad septate hyphae. Clamp connections present in stipe.

Collection examined - India, Punjab, Patiala (251 m), village Bahadurgarh $\left(30^{\circ} 19^{\prime} 49.5^{\prime \prime} \mathrm{N}\right.$ to $76^{\circ} 23^{\prime} 41.2^{\prime}$ E), growing scattered on leaf litter in a garden, 17 September 2011, Narinderjit Kaur, PUN 4688 (Holotype).

Remarks - The macroscopic and microscopic details of the above examined collection do not match with any of Lepiota species. It is somewhat similar in its color tones, basidiospore size 


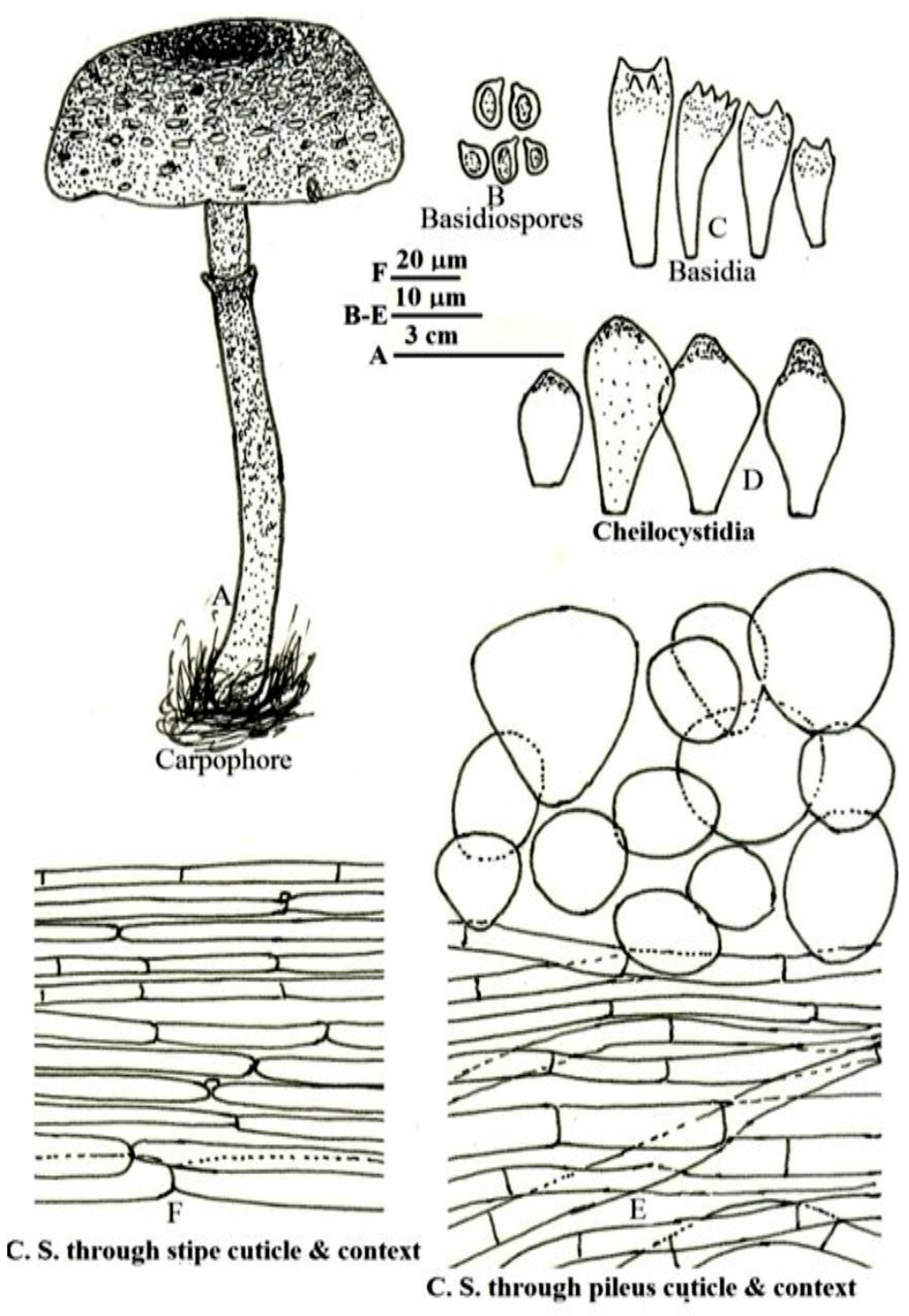

Fig. 1 - A-F Lepiota punjabensis sp. nov. A Carpophores. B Basidiospores. C Basidia. D Cheilocystidia. E C. S. through pileus cuticle \& context. F C. S. through stipe cuticle \& context.

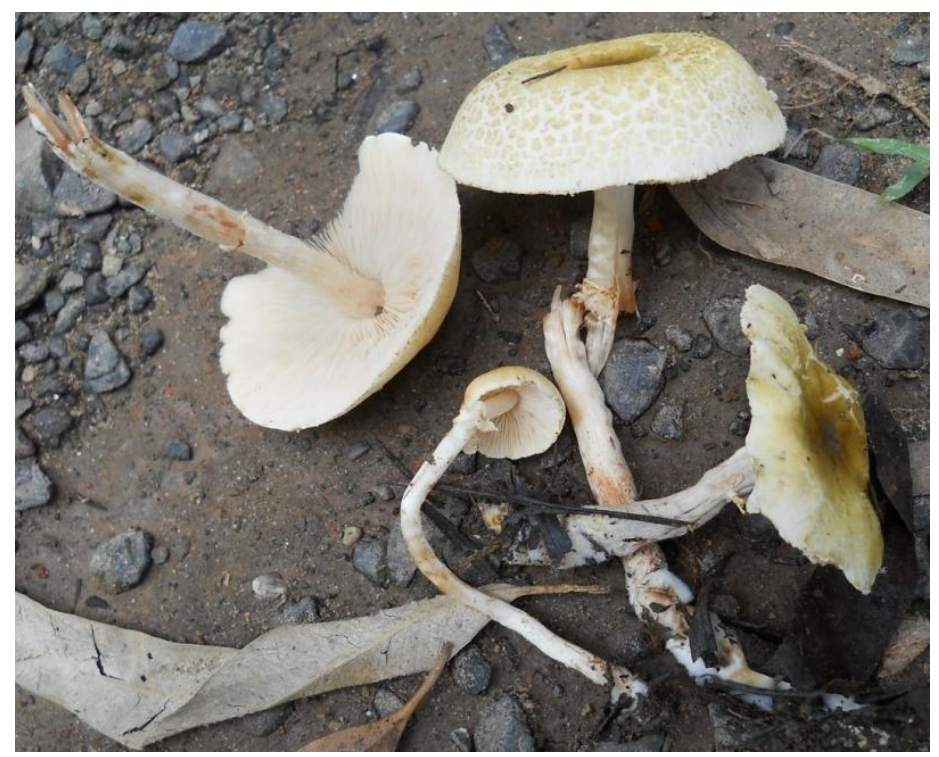

Fig. 2 - Lepiota punjabensis sp. nov.: Carpophores showing olivaceous green, depressed centre. 
and the presence of mycelial mat at the stipe base to Lepiota luteophylla Sundberg as described by Sundberg (1971). In the literature, the size of the cap of the carpophore is given as upto $4.0 \mathrm{~cm}$ broad, where as in PUN 4688, the cap is much larger varying in length from $7.0-12 \mathrm{~cm}$ in breadth. The stipe has a well represented annulus in our specimen and it is not represented by an appressed zone of tissue. The stipe is white $\left(1 \mathrm{~A}_{1}\right)$ changing to reddish brown $\left(8 \mathrm{D}_{6}\right)$ on bruising in PUN 4688 , but it is never pale yellow or unchanging as given in the literature. Spore print is white in Lepiota luteophylla Sundberg, but grayish orange $\left(5 \mathrm{~B}_{3}\right)$ in PUN 4688. Cheilocystidia are absent in Lepiota luteophylla Sundberg, where as in PUN 4688 fusoid to ballon shaped, granular, encrustrated cheilocystidia are present. Gill edges are fertile in Lepiota luteophylla Sundberg, but edges are heteromorphous in PUN 4688. Thus taking into consideration the above meaningful differences, a new species Lepiota punjabensis sp. nov. is being proposed as new to Science.

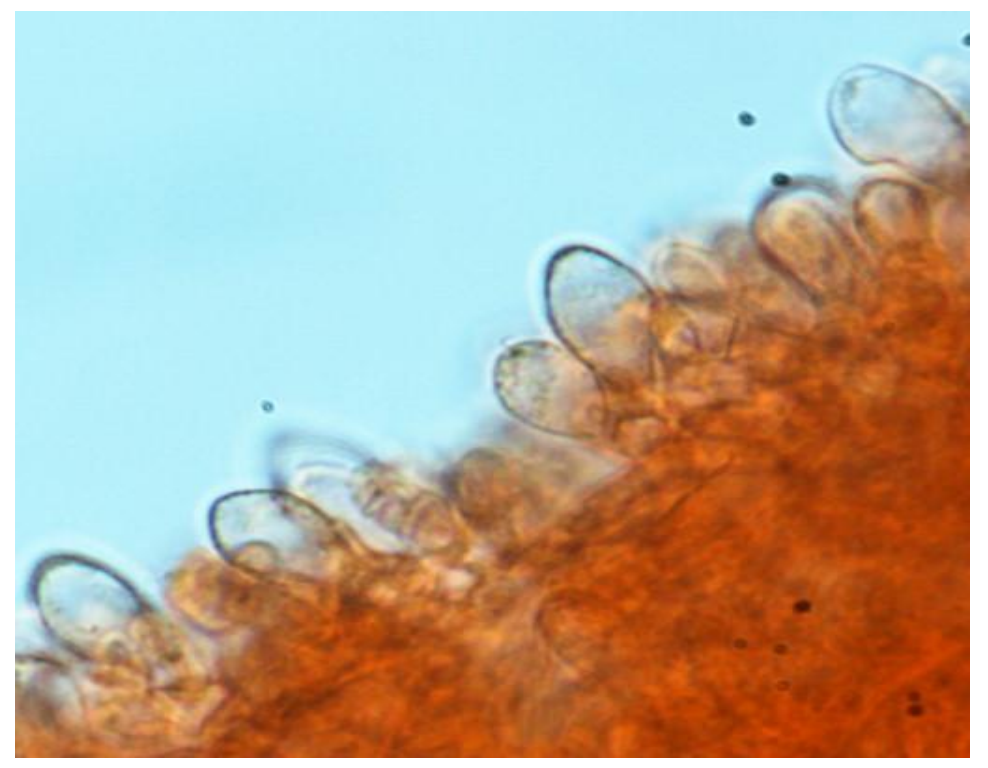

Fig. 3 - Lepiota punjabensis sp. nov.: Cheilocystidia with encrustrated apices.

Volvariella indica M.K. Saini, N.J. Kaur, N.S. Atri sp. nov.

Figs. 4-8 Mycobank no.: MB 804782

Etymology - The name of species is based on the Indian nation.

Pileus 2.2-3.5 cm broad, campanulate to convex; very shining, white; Lamellae free, sub distant pinkish brown; Stipe3.8-6.8 cm long, 0.4-0.6 cm broad; volva fleshy, lobed; basidiospores 10.7 $14.32 \times 7.1-8.95 \mu \mathrm{m}$, guttulate; pleurocystidia and cheilocystidia absent; pileus cuticle ixocutis, gelatinized; clamp connections absent throughout.

Carpophores 4-7 cm in height. Pileus $2.2-3.5 \mathrm{~cm}$ broad, campanulate to convex; broadly umbonate; surface moist, very shining, white, unchanging; scaly, scales appressed fibrillose, scattered all over the surface; cap surface covered with white cottony mass all over and volval remnant patch present in the centre of the carpophores; margin irregular, striate, striations along margins; cuticle half peeling; flesh upto $0.2 \mathrm{~cm}$ thick, off white, unchanging; taste mild and odour spicy. Lamellae free, unequal, sub distant, upto $0.3 \mathrm{~cm}$ broad, pinkish brown, edges white, wavy, normal. Stipe central, $3.8-6.8 \mathrm{~cm}$ long, $0.4-0.6 \mathrm{~cm}$ broad and $1.2 \mathrm{~cm}$ broad in young just opened specimens, concolorous with pileus, equal in diameter throughout with distinctly bulbous base, solid, scaly; exannulate; volva fleshy, lobed in young carpophores whereas in mature fruiting bodies the volva is in the form of fleshy to membranous patches tightly adhering to the stipe base, creamish white.

Basidiospores $10.7-14.32 \times 7.1-8.95 \mu \mathrm{m}$ (excluding apiculus), $(\mathrm{Q}=1.55)$, ellipsoid, smooth, thick walled, guttulate, inamyloid; apiculate, apiculus upto $1.8 \mu \mathrm{m}$ long, open pore type. Basidia $26.8-35.8 \times 8.95-12.53 \mu \mathrm{m}$, clavate, granular to hyaline, 2-4 spored; sterigmata upto 2.7 


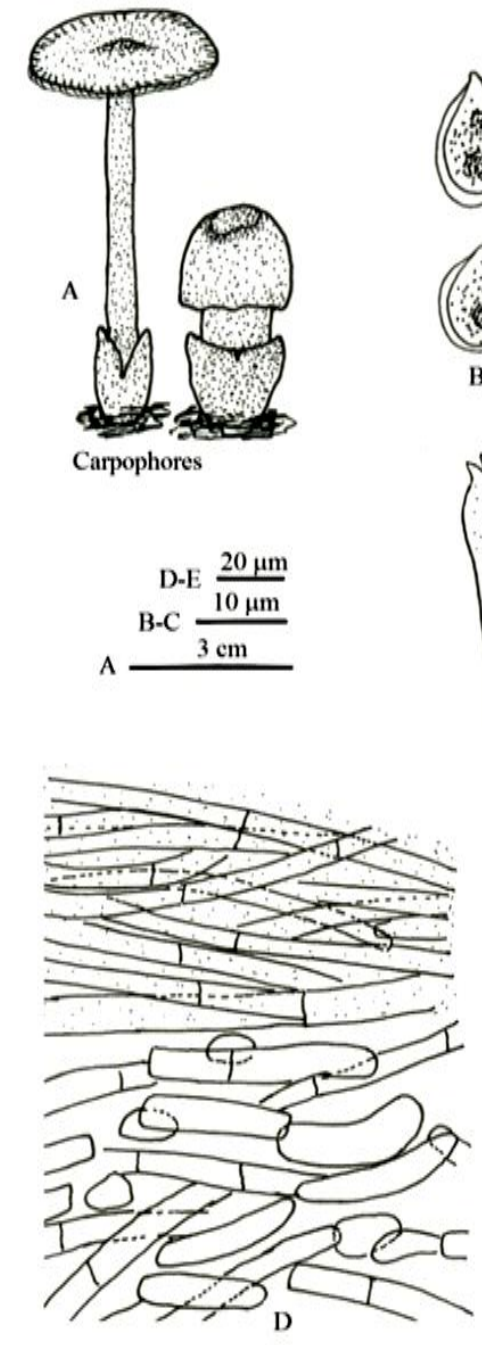

C.S. through pileus cuticle \& context

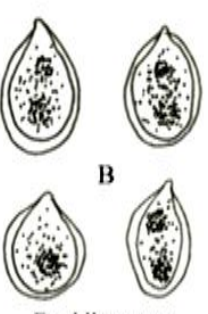

Basidiospores
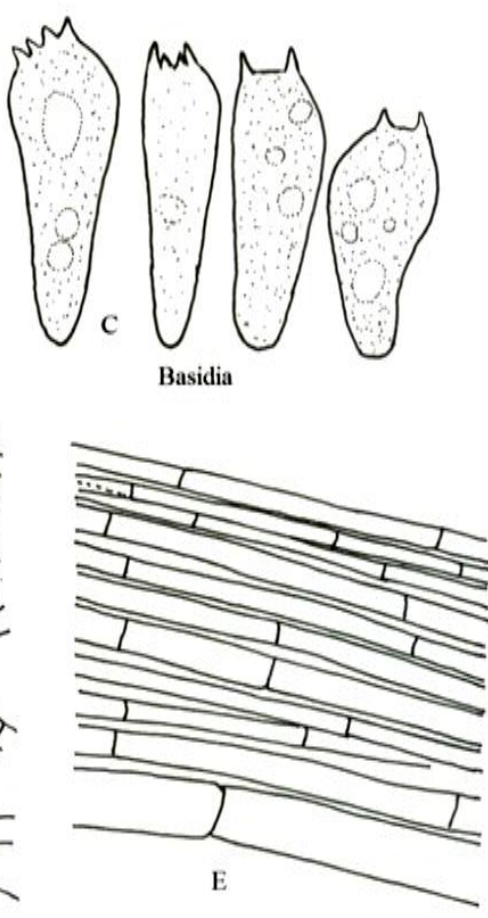

C.S. through stipe cuticle \& context

Fig. 4 - A-E Volvariella indica sp. nov.: A Carpophores. B Basidiospores. C Basidia. D C.S. through pileus cuticle \& context. E C.S. through stipe cuticle \& context.

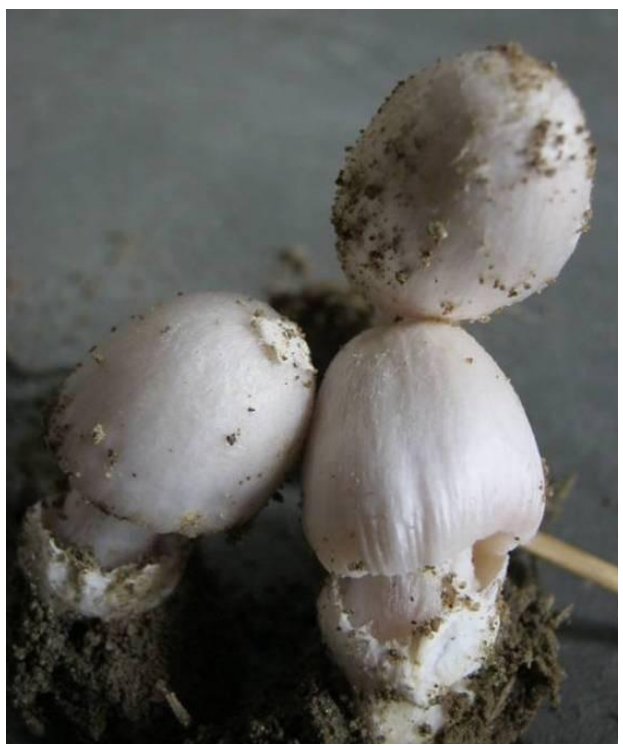

Fig. 5 -Volvariella indica sp. nov.: Young Carpophores 


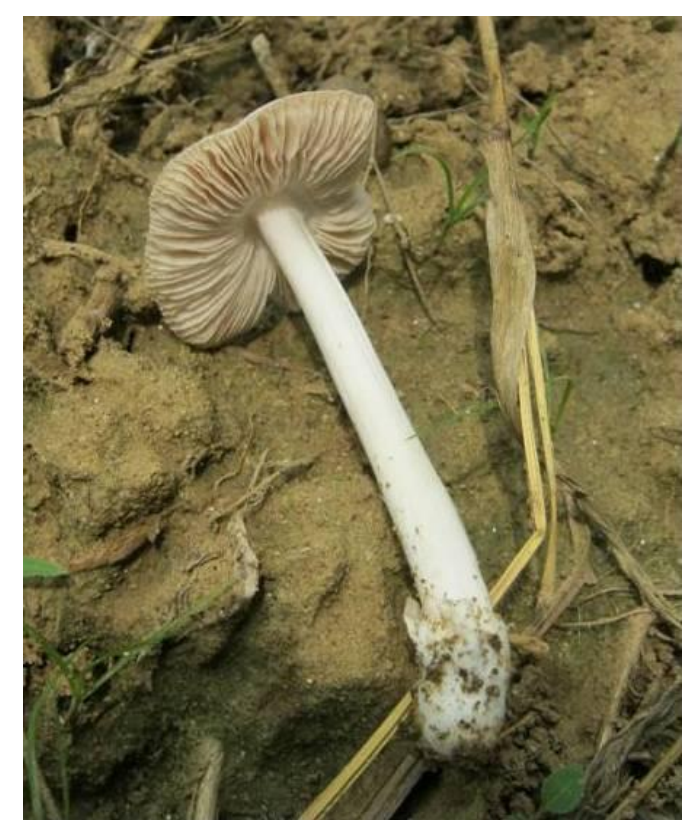

Fig. 6 - Volvariella indica sp. nov.: Mature Carpophore.

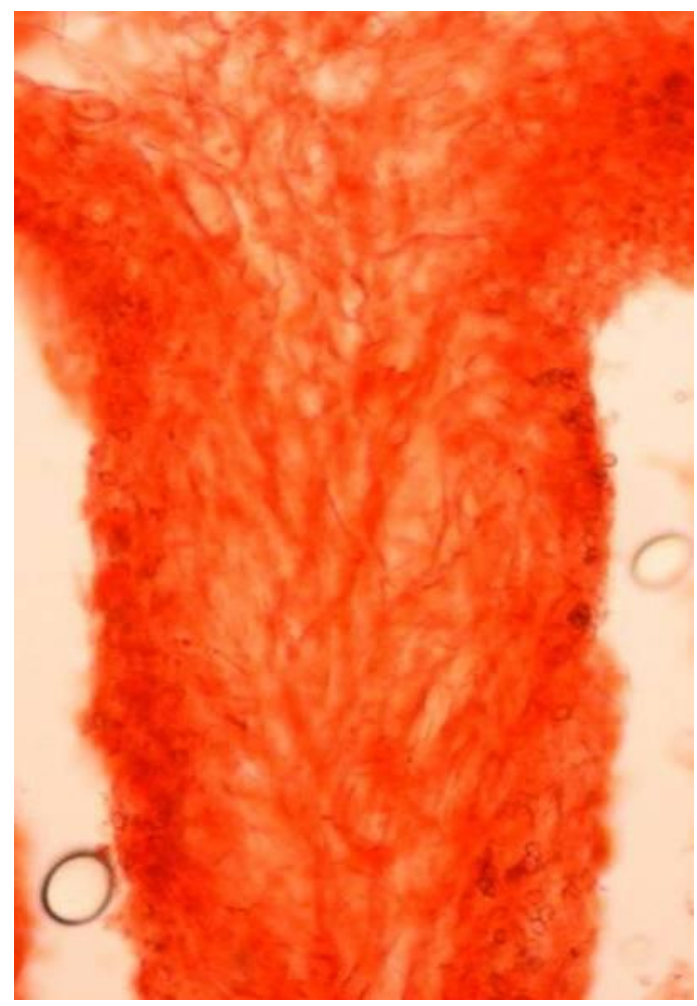

Fig. 7 - Volvariella indica sp. nov.: Lamellae showing convergent trama.

$\mu \mathrm{m}$ long, pointed. Pleurocystidia and cheilocystidia absent. Gill edges sterile. Carpophore context homoiomerous. Pileus cuticle ixocutis, gelatinized, made up of horizontally tangled, granular, septate upto $11 \mu \mathrm{m}$ broad hyphae; context made up of loosely arranged, septate, upto $16 \mu \mathrm{m}$ broad hyphae. Hymenophoral trama convergent. Stipe cuticle hyphal, smooth, made up of longitudinally tangled, septate, upto $18 \mu \mathrm{m}$ broad hyphae. Clamp connections absent throughout.

Collection examined- India, Punjab, Hoshiarpur $(295 \mathrm{~m})$, village Jahan Khelan $\left(31^{\circ} 31^{\prime} 46.5^{\prime \prime} \mathrm{N}\right.$ to $\left.75^{\circ} 55^{\prime} 12^{\prime \prime} \mathrm{E}\right)$, growing scattered among grasses in open field on humicolous soil, 7 August 2011, Narinderjit Kaur, PUN 4699 (Holotype). 


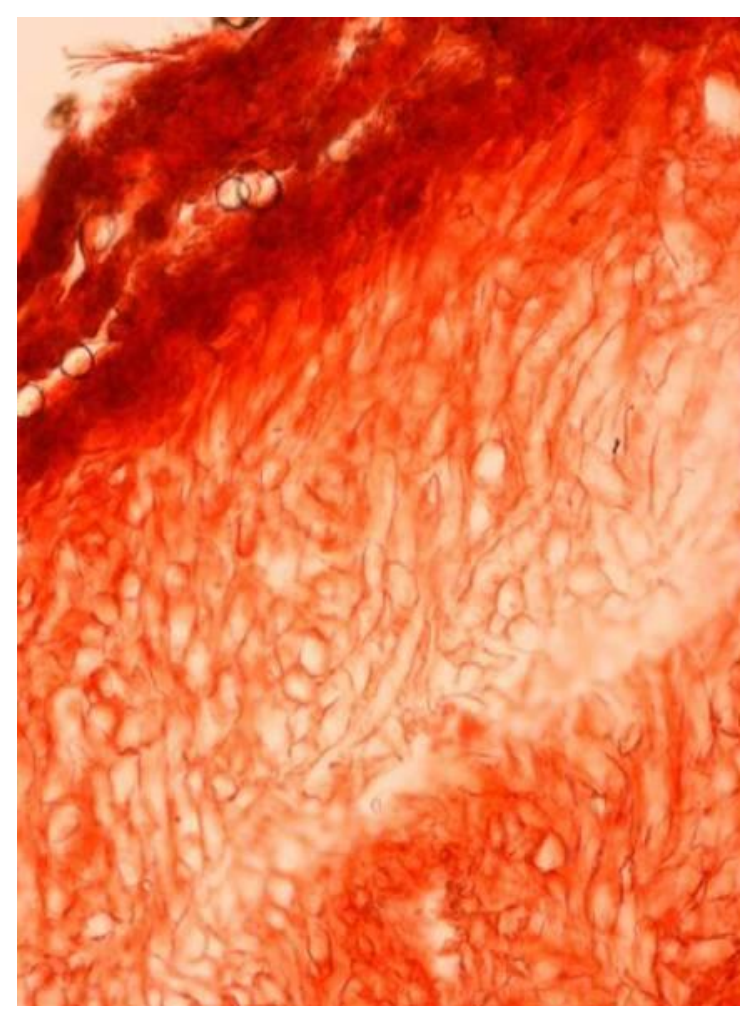

Fig. 8 - Volvariella indica sp. nov.: C.S. through pileus cuticle

Remarks - The basidiospore size in presently worked out collection is more than $10 \mu \mathrm{m}$. Thus, this genus belongs to Strips Speciosa of genus Volvariella Speg. Under this section, two species of Volvariella viz. Volvariella speciosa and Volvariella media are described by Orton (1986). The macroscopic and microscopic details of PUN 4699 do not match with either of the species. The present collection differs from Volvariella speciosa in having smaller carpophore size i.e. $2.2-3.5 \mathrm{~cm}$ broad cap rather than 5.0-8.0 (10) $\mathrm{cm}$ broad given in literature. The basidiospore size of $V$. speciosa is (11) $13-18 \times(7.5) 8-10 \mu \mathrm{m}$, where as it is much smaller in PUN 4699 i.e. (8.0) $11-4.32 \times(6.8) 8.0-9.6 \mu \mathrm{m}$; also pleurocystidia and cheilocystidia are present in Volvariella speciosa, but these are lacking in our specimen. On the other hand, the basidiospore size of Volvariella media is $11-16 \times 7.0-8.0 \mu \mathrm{m}$, but the basidiospores of PUN 4699 are comparatively 11-14.32 × (6.8) 8.0-9.6 $\mu \mathrm{m}$, also pleurocystidia are present in Volvariella media but not in our specimen. The presently worked out specimen is unique in its characters, differs from $V$. speciosa and $V$. media in key characters, thus a new species Volvariella indica sp. nov. is being proposed as new to science under the Strips Speciosa.

\section{Acknowledgements}

Thanks are due to the Head, Department of Botany, Punjabi University, Patiala for providing laboratory facilities. We are indebted to UGC and DST for financial assistance.

\section{References}

Atri NS, Kaur A, Kour H. 2005 - Wild Mushrooms- Collection and Identification. In: Frontiers Mushroom Biotechnology. (Rai RD, Upadhyay RC, Sharma SR eds). NRCM Chambaghat, Solan, pp. 9-26.

Kirk PM, Cannon PF, Minter DW, Stalpers JA (eds). 2008- Dictionary of Fungi, $10^{\text {th }}$ edn. CABI Publishing, UK. 
Kornerup A, Wanscher JH. 1978 - Methuen Handbook of Colours, $3^{\text {rd }}$ edn. Eyre Methuen. London, 252.

Orton PD. 1986 - Pluteaceae: Pluteus and Volvariella. British Fungus Flora Agarics and BoletesEdinburgh: Royal Botanic Garden.

Pegler DN. 1977 - A preliminary agaric flora of East Africa. Kew Bull. Addi., Ser.6. Her Majesty Stationary Office Pp. 615.

Singer R. 1986 - The Agaricales in Modern Taxonomy. 4th Ed. Sven Koeiltz Scientific Books, Germany. pp. 981.

Sundberg WJ. 1971 - A new species of Lepiota. Mycologia 63 (1): 79-82. 